\title{
SOBRE EL ARTE DE LOS NUEVOS MEDIOS
}

Artículo de reflexión

\section{Célia Riboulet}

Universidad Autónoma del Estado de México / celia_riboulet@hotmail.com

Joven artista y teórica francesa, Célia Riboulet inicia su trayectoria artística en 2001, en el Departamento de Artes Visuales de la Universidad de Toulouse le Mirail, Toulouse. En 2010, da un curso teórico sobre arte digital en el Centro Nacional de las Artes (México), que concluye en mayo-junio 2011 con un curso práctico y una muestra de Videoarte Latinoamericano en junio 2013. En agosto 2011, entra de profesor de tiempo completo en la Universidad Autónoma del Estado de México en la nueva Licenciatura de Arte Digital. En agosto 2012 gana una beca de apoyo a la investigación en Artes y Medios del Centro Multimedia del CENART (México). Publica varios artículos en revistas indexadas sobre el videoarte en Latinoamerica (Brasil, México, USA). 
RIBOULET C, (2013) Sobre el arte de los nuevos medios, Calle 14, 7 (10), 54-57.

\section{RESUMEN}

Las tecnologías de información y comunicación han transformado completamente las prácticas artísticas contemporáneas, modificando las nociones tradicionales de tiempo, autor, medio, soporte, obra, realidad y espectador, y dando lugar a un nuevo género artístico: el arte digital. El presente póster analiza sus principales características con base en el estudio de los textos de Edmond Couchot y Jean-Pierre Balpe.

\section{PALABRAS CLAVES}

Arte digital, hibridación, autor único/múltiple, tiempo circular, interactividad

\section{ON THE ART OF NEW MEDIA}

\section{ABSTRACT}

Information and communication technologies have completely transformed contemporary art practices, changing traditional notions of time, author, medium, support, work, reality and the spectator, and giving rise to a new genre: digital art. The following poster discusses its main features based on a study of texts by Edmond Couchot and Jean-Pierre Balpe.

\section{KEY WORDS}

Digital art, hybridization, multiple/unique author, circular time, interactivity

\section{SUR L'ART DES NOUVEAUX-MÉDIAS.}

\section{RÉSUMÉ}

Les technologies de l'information et de la communication ont transformée complètement les pratiques artistiques contemporaines, en modifiant les notions traditionnelles de temps, auteur, médias, support, œuvre, réalité et spectateur, en donnant lieu à un nouveau genre artistique : l'art digital. Le présent article analyse ses principales caractéristiques, en se basant sur l'étude des textes de Edmond Couchot et Jean-Pierre Balpe.

\section{MOTS CLÉS}

Art digital, hybridation, auteur unique/multiple, temps circulaire, interactivité

\section{SOBRE A ARTE DOS NOVOS MEIOS}

\section{RESUMO}

As técnicas de informação e comunicação têm transformado completamente as práticas artísticas contemporâneas, modificando as noções tradicionais de tempo, autor, meio, suporte, obra, realidade e espectador, e dando lugar a um novo gênero artístico: a arte digital. Este cartaz 
analisa suas principais características com base no estudo dos textos de Edmond Couchot e Jean - Pierre Balpe.

PALAVRAS-CHAVE

Arte digital, hibridação, autor único / múltiplo, tempo circular, interatividade

\section{MUSU RRURRAIKUNAMANDA}

\section{UCHULLAIACHI}

Kuanpunchaurramanda rrurraskakuna rrimaikuna parrlaikuna trrukaskakuna tukui ima kunauarramanda rrurrai iachaskakunata, trrukaspa ñugpamanda punchakuna rrigsiskakunata, rrurradurr rruna, medio, charrirridirru, rrurrai, sutipa kagta i kauadurrkuna, churraspa sug luarrpi sug musu rrurraikuna apamuspa: makikunaua rrurraikuna. Kai kilkaska kaua kikinpa rrurraikuna, kilkaskakunata Edmond Couchot y Jean-Pierre Balpe paikunapata iachaikuspa.

\section{RRIMANAKUI}

Makikunaua rrurraikuna, chapuska, suglla rrurradurr rruna/chapuska, punchakuna muiui

Recibido el 21/03/2012

Aceptado el 23/09/2012 


\section{Un arte del multimedia}

El arte digital es un arte perteneciente al multimedia, que trata datos provenientes del campo del sonido, del texto, de las imágenes fijas y también en movimiento. Lo que lo caracteriza no es, por lo tanto, la mezcla de los géneros (estilos) sino la creación y la constitución de un lenguaje propio. Lo que le interesa son las posibilidades expresivas propias de sus diferencias. Por ejemplo, una obra clásica de literatura grabada en un disco, queda como una obra clásica. Si lo digital es capaz de proyectar imágenes sobre bailarines, el arte digital solamente empieza cuando estas imágenes se vuelven componentes del cuerpo del bailarín o del actor. Este arte no consiste en complementar prácticas ya clásicas, sino en proponer situaciones expresivas y semióticas inéditas. Si puede ponerse al servicio de otros tipos de arte, tales utilizaciones no constituyen, por lo tanto, un arte digital. Del mismo modo que lo digital puede, a partir de ahora, complementar todos los aspectos de las actividades humanas, también puede ser un instrumento y un dominio artístico particular.

Podríamos decir que el arte digital es "conmutativo" (Guillaume, 1998), ya que asegura una perpetua transposición dinámica de los datos de un medio hacia otro. En el transcurso de estas modificaciones, aparece la producción de datos nuevos. Los objetos de que trata el arte digital son siempre heterogéneos y complejos. Las instalaciones pueden así, simultáneamente, utilizar procedimientos de interacciones que se manifiestan a través de diferentes medios. El terreno del arte digital está hecho de cruces de toda clase. Siempre propone objetos heterogéneos aún no catalogados; es una mezcla compleja de lo material y lo inmaterial, de azar y de obligaciones, de aperturas y cierres. La mayoría de las obras de los artistas resultan ser objetos híbridos en los cuales las posibilidades técnicas sirven para multiplicar las posibilidades de expresión. Esta hibridación es, sin duda alguna, uno de los aspectos más interesantes del arte digital, porque no solo rompe las barreras tradicionales entre los diferentes artes, sino también introduce el enfoque artístico en áreas que hasta entonces estaban alejadas.

La intención central ya no es la pluri o multisensorialidad, sino lo que Jean-Pierre Balpe llama la co-sensorialidad (2000). Se trata de especificar relaciones inéditas en una representación que ya no es exterior frente al espectador, pero que lo engloba y lo trata, a la vez, como participante del mundo sensorial propuesto. Además, a pesar de las apariencias comunes, también existe una gran diferencia entre la pantalla de video y la del computador: frente a la de video, el espectador se queda en la retaguardia y acepta ir de su mundo hacia el que se le propone; por otra parte, en la pantalla del computador, el espectador está dentro y es ese mundo al que tiene que aceptar ir.

\section{Un autor único con infinitas signaturas}

Para ser eficaces, estas propuestas artísticas tienen que aparecer con la fuerza de su evidencia, y la técnica tiene que desaparecer delante de la expresión perceptiva. El artista es una fuerza de proposición que afirma una visión particular y subjetiva. Por esta razón precisa, el autor -ya sea uno o múltiple- no puede totalmente desaparecer ante lo colectivo. El estatuto de la obra, del autor y del espectador sufre fuertes alteraciones, y el triángulo delimitado tradicionalmente por ellos tres ve su geometría modificarse. Se puede decir que este triángulo tiende a transformarse en círculo; y sobre este círculo móvil, la obra, el autor y el espectador no ocupan ya lugares estrictamente definidos ni identidades impermeables, estos se intercambian constantemente, se cruzan, se hibridan. Para Edmont Couchot (1998):

La historia se compone de dos: está, parcial pero efectivamente, la obra del que mira, la proyección de sus reacciones de sus pensamientos, de su subjetividad; y, por otro lado, está el resultado de 
dos sujetos que hibridan su singularidad respectiva a través de una interfaz. Y cuando esta obra pone en relación, vía una red digital, una multitud de otros actores navegando en el mismo espacio dialógico, esta responsabilidad se comparte, se fractaliza, en miles de coautores. Entonces la historia se compone de varios.

Pero, aunque varios autores realizan la obra al navegar por la red, la concepción artística implica una dirección: la fuerza subjetiva de una mirada lateral. El autor es el que, responsable de esta dirección, da el cuerpo central y el sentido del proyecto. Su originalidad está siempre presente, cualesquiera que sean las interacciones y las técnicas convocadas.

\section{Un tiempo circular}

Dinámicas por naturaleza, las obras producidas por el arte digital se inscriben siempre en un tiempo. Este último se distingue de los modos estáticos institucionalizados que constituyen la mayoría de las veces las exposiciones. La evolución en el tiempo es un componente de la expresión: lo que se produce ahora no se producirá nunca más de manera idéntica, no hay mirada retrospectiva posible. Lo que se produce ahora se puede también reproducir en cualquier otro momento, así como nunca producirse o reproducirse. El tiempo ya no es lineal, sino circular. En el acontecimiento del arte digital, el pasado, el presente y el futuro se encuentran sin cesar; se introduce un ritmo que le es propio.

La repetición, con todas sus sutilezas y ardides en cada una de sus manifestaciones, es tan original como el original mismo. Si se pone más adelante el devenir de la creación en alguno de sus momentos, cada manifestación del arte digital abre la creación de una memoria. Lo que se percibe está en relación con lo que ya fue percibido y con lo que es susceptible de serlo. El que percibe no elige lo que va a experimentar porque solamente puede tener una intuición aproximativa, pero sí puede seguir percibiendo y, sobre todo, intentando descubrir, bajo la instantaneidad de la percepción, su sustancia. Así, el espectador es el único que tiene el poder de construir la unidad de su percepción. "La unidad no para de ser maltratada e impedida en el objeto, mientras un nuevo tipo de unidad triunfa en el sujeto" (Deleuze y Guattari, 1980).
Al jugar así, sin cesar, sobre la oposición entre la unidad profunda de los posibles y la singularidad perceptible de los acontecimientos, el arte digital propone siempre, a la vez, una "tecniquización" y una provocación del tiempo real; como si se quisieran reconciliar las dos formas de arte que, según Georges Duthuit (1961), parecen oponerse en la historia: un arte de la fijación definitiva que aspira a la fractalidad, la distancia, la estabilidad definitiva del objeto inmutable y del museo; y un arte que juega con el accidente y lo imprevisible de lo real, buscando la diversidad de los contextos, la participación y la representación.

\section{Un lenguaje a formar}

Cuando el arte digital está regido por una construcción técnica de posibles en la cual la intervención del público queda siempre regulada por el control más o menos visible de un autor, integra a la vez el tiempo y la presencia del espectador. Este último ya no crea el cuadro, sino que se vuelve materia de él. En el arte digital, la obra es al mismo tiempo objeto y no-objeto. Es objeto en cuanto a la materialización obligada de sus instalaciones y la escritura concreta de los programas que delimitan sus posibilidades; y es no-objeto por la infinidad de sus manifestaciones perceptivas. El arte digital objetiviza el acontecimiento, que hace acceder al nivel material del arte. El acontecimiento ya no es como en el performance o en el happening una afirmación del arte, pero es el elemento de un lenguaje a formar.

En los sistemas artísticos digitales interactivos, el espectador no puede conocer las reglas a las cuales sus comportamientos se van a someter. Estas pertenecen solamente al dispositivo al cual está confrontado el espectador aquí y ahora. Las reglas cambian de un dispositivo al otro. También pueden, si el artista lo quiere, cambiar de un momento a otro en el mismo dispositivo. El espectador, al mantenerse en posición de sorpresa casi permanente, posee elecciones que son, en su mayor parte, desconocidas. El espectador debe intentar siempre entender, anticipar; y para ello tiene que ponerse en la situación de observador. "El observador está al centro del proyecto creativo, y no en la periferia. El arte ya no es una ventana hacia el mundo, pero sí una puerta de entrada a través de la cual el observador está invitado a entrar en un mundo de interacciones y transformaciones." (Ascott, 1997). 


\section{El arte digital, una experiencia virtual de lo real}

El arte digital estimula la racionalidad de un dominio que, a priori, está desprovisto de ella, porque obliga a una construcción reflexiva:

Los mundos virtuales son nuevos laberintos. Nos confrontan con nuevas experiencias del espacio y del cuerpo y con paradojas de un nuevo género. El objeto es tratado como una propuesta que toma sentido con la condición de responderlo, de encontrar lo que se tiene que hacer, y de hacerlo. Pero, sobre todo, nos obliga a hacer un esfuerzo de inteligibilidad, a una mejor inteligencia de los lienzos y de los nudos, entrelazando las realidades y las apariencias, las ilusiones y los síntomas, las imágenes y los modelos. (Balpe, 2000)

El arte digital transforma la percepción en acción. Y contrariamente a lo que pueden afirmar algunos de sus detractores, lo virtual no mata lo real. La experimentación enriquece la experiencia de lo real, porque señala las carencias y porque permite explorar algunas formas límite, participando como en una mutación de la sensibilidad. Constituye lo que Rosnay (1995) llama "la introsfera": el lienzo imaginario entre lo real y lo virtual, la capacidad de volver a juzgar lo real en relación con la percepción realista de lo imaginario.

El arte digital confronta al hombre con los cambios del mundo y lo pone a distancia, en una forma de simulación, experimentación de su auto-tecniquización. Y si vimos que el desafío principal de las prácticas artísticas reside en la exploración de las posibilidades de producción y de creación material y formal ofrecidas por las nuevas tecnologías, otro desafío mayor sería el de experimentar con las posibilidades de reconfigurar la esfera pública que ellas ofrecen, de transformar, sobre todo, los dispositivos de distribución social, con las posibilidades de alterar los modos de exposición, de presentación pública de las prácticas artísticas.

\section{Referencias}

Ascott, Ray (1998). Arte en red. Tokyo: A. Takada \& Y. Yamashita.

Balpe, Jean-Pierre (2000). Contextos del arte digital. Paris: Hermes.
Blanchot, Maurice (1959). El libro por venir, Ideas. Madrid: Trotta.

Couchot, Edmond (1998). La tecnología en el arte. De la fotografía a la realidad virtual. Paris: Chambon.

Deleuze, Gilles, \& Guattari, Felix (1980). Mil Mesetas.

Paris : Les Éditions de Minuit.

Duthuit, Georges (1961). La imagen en sufrimiento.

Paris: Georges Fall.

Guillaume, Marc (1998). ¿Dónde van las autopistas de la información?. Paris: Descartes \& Cie.

Rosnay, Jöel de (1995). El hombre simbiótico, miradas sobre el tercer milenario. Paris: Seuil. 




Púrpucos. Catalina Contreras Rodríguez. 2012 


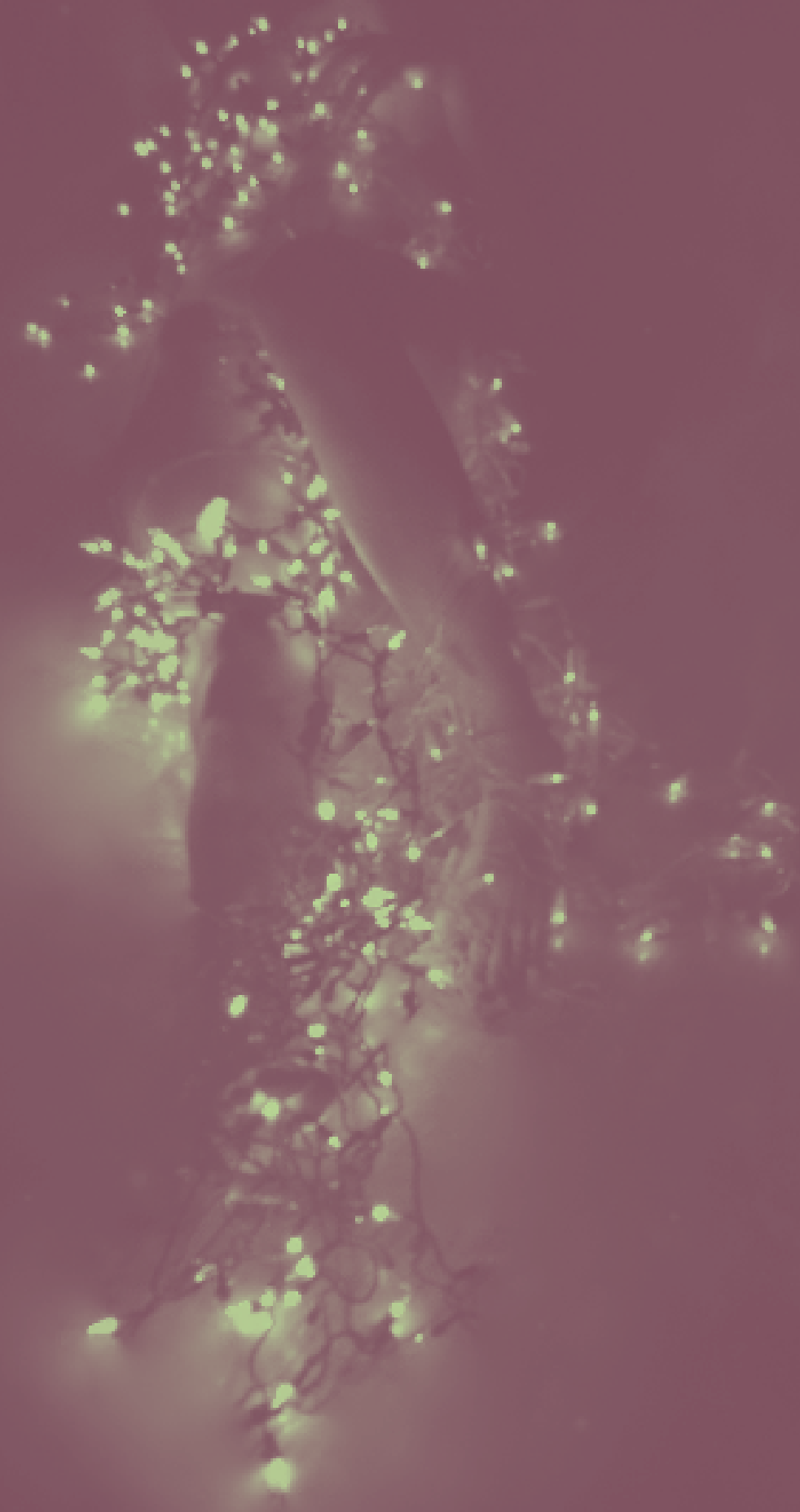

